\title{
Multiple time-scale optimization for the dispatch of integrated energy system based on model predictive control
}

\author{
Yajie Huang ${ }^{\mathrm{a} *}$, Junyong $\mathrm{Wu}^{\mathrm{a}}$, Xingyan $\mathrm{Niu}^{\mathrm{b}}$, Shiqiao Gao ${ }^{\mathrm{b}}$ \\ ${ }^{a}$ a Electrical Engineering Department,Beijing Jiaotong University,Beijing,100044,China \\ ${ }^{b b} R \& D$ China Center, Électricité de France,Beijing,100005, China
}

\begin{abstract}
With the development of society and economy, energy shortage is increasingly serious. How to improve the utilization rate of energy is main problem at present. The integrated energy system, is to comprehensively plan, coordinately control, intelligently dispatch and multiply interact with multiple energy flows such as cold, heat, power and gas, which has broken the existing models of individual plan, design and operation of each energy supply system, and becomes a new model of future energy utilization. In this paper, a multiple time-scale cooperative optimization is proposed based on model predictive control, which is for the control optimization of energy storage, cold storage and heat storage to fulfill the minimization of total operation cost of integrated energy system based on the charge mode of maximum demand. The implementation of cost optimization has 3 steps which are month-in-advance off-line planning, day-ahead dispatch and short-term online MPC control. This optimization strategy not only reduces the power imbalance of control system caused by the error of model prediction of renewable energy and load, but also ensures the overall optimization efficiency of system. A park in Beijing is taken as an example to analyze and verify the effectiveness of the proposed model and algorithm.
\end{abstract}

Keywords: integrated energy system, model predictive control, coordinated optimization, multiple time-scale control strategy of energy storage

\section{Introduction}

As the development of society, Energy consumption for residents and industrial production has increased greatly. Under the global shortage of fossil energy and increasingly severe environment pollution, the concept of integrated energy system is proposed for the optimization of energy structure and the improvement of energy efficiency and ecological environment. 2018 Notice of the Guidance for the Energy Works, issued by National energy administration, points out that make efforts to solve the consumption, enhance energy storage for peak regulation and market compensation, promote the construction of demonstration project which are 'internet+intelligent energy', multiple complementarity $\&$ integrated optimization, micro power grid of new energy, in-grind micro power grid and technical experiment of energy storage, and vigorously popularize the application based on the pilot.

Integrated energy system is the next-generation intelligent system, which deeply combines and closely interacts the resource, gird, load and storage of multiple energies. It applies systematization, integration and refinement to analyze, design, operate and manage the energy generation, transportation, storage and usage of whole energy system for the great improvement of sustainability, safety and reliability of whole energy system and the reduction of energy price. And more and more research focus on the coordinately optimal control for integrated energy system at present. A literature review of control methods was reported in Refs[1], with an emphasis on the theory and applications of model predictive control (MPC) for heating, ventilation, and air conditioning (HVAC) systems. Refs[2] presents a hierarchical real-time optimization with mathematical formulations to achieve optimal operation by using simple numerically tractable model predictive control strategies for an islanded microgrid. An optimal control strategy is proposed in Refs[3] to coordinate energy storage and diesel generators to maximize wind penetration while maintaining system economics and normal operation performance. It has been shown in Refs[4]

\footnotetext{
* Manuscript received July 23, 2018; revised March 12, 2019.

Corresponding author. E-mail address: 16121460@bjtu.edu.cn

doi: $10.12720 /$ sgce.8.3.263-270
} 
that the proposed operation and schedule strategy can lead to an improved microgrid economic dispatch with the help of BESS.A Model Predictive control is considered for MILP optimization problem in Refs[5] to the study behavior of the microgrid system during uncertainties while satisfying operational constraints and a time varying requests. It proposes a new smart microgrid configuration and an innovative power control concept for future grids in Refs[6], which utilizes model predictive control (MPC) to assist in coordinating the plethora of generation and load combinations. A building energy demand reduction has been developed in Refs[7] via model predictive control to demonstrate the effectiveness in saving energy and demand costs. The Building Controls Virtual Test Bed software was employed as middleware to link Energyplus and Matlab and the real-time data exchange between the two programs enabled implementation of closed-loop controllers. The development of optimization-based distributed scheduling strategies for the coordination of an energy internet (EI) with multi-microgrids with consideration of forecast uncertainties is reported in Refs[8] and a game theory based parallel distributed optimization algorithm is proposed to coordinate the competitive objectives of the microgrids with only a little information interaction in this paper.

\section{The Architecture of Integrated Energy System And Strategy for Energy Optimization}

\subsection{The architecture and main components of the integrated energy system}

In this paper, the integrated energy system includes the following main components: micro-turbine, ice storage air conditioner, electric refrigerator, gas boiler, heat recovery steam generator, lithium bromide compressor, heat storage device and energy storage device. Figure 1 shows the framework of integrated energy system, which organically integrates various forms of energy such as gas, electricity, cooling and heat, and the energy flow of the components is also marked.

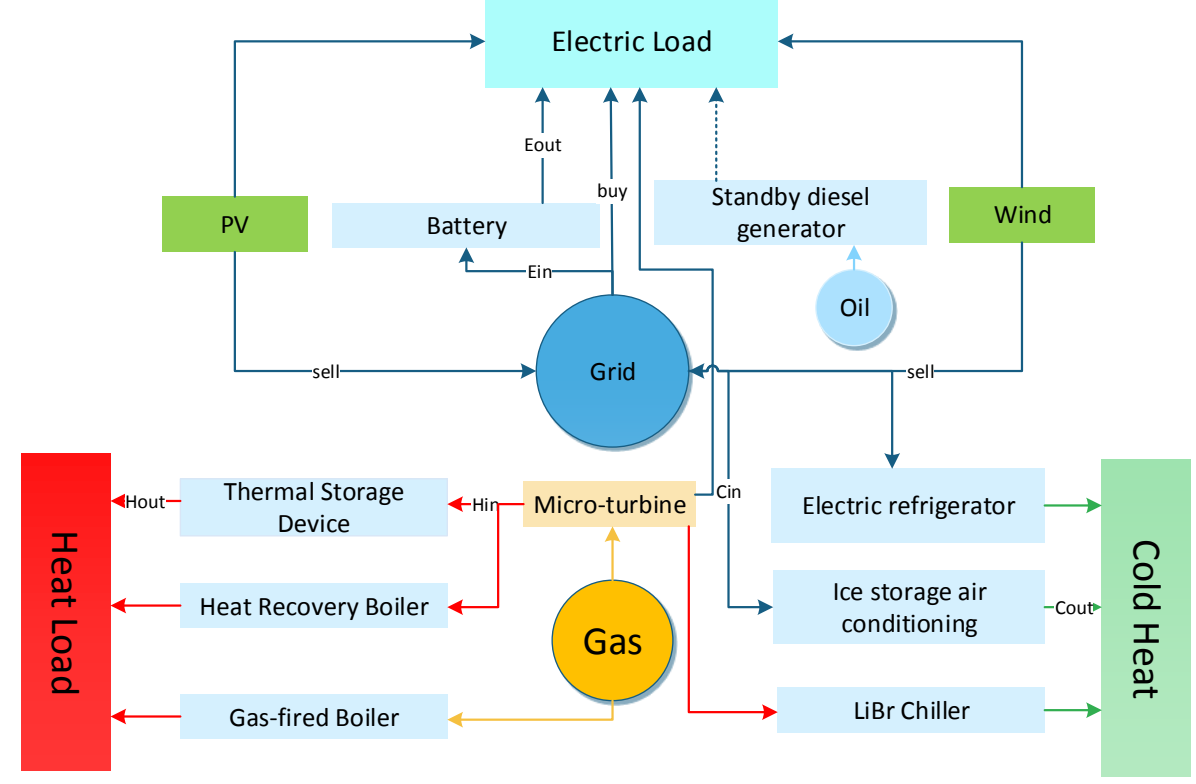

Fig. 1. The Architecture of the Integrated Energy System and Energy Flow

\subsection{Energy optimization strategy}

Energy optimization strategy ${ }^{[11-13]}$ is divided into three steps: off-line month-in-advance planning, dayahead dispatch and online short-term MPC control. At present, for industrial power users in China, in addition to time-of-use electricity price, two price systems are generally implemented. That is, the electricity costs consist of two parts: basic electricity cost and over-capacity energy cost. The offline month-in-advance planning is mainly to calculate the user's maximum demand for the month, and the 
users whose basic electricity cost is calculated based on the maximum demand needs to make agreement with the electric power department in advance to determine the maximum electricity consumption. In order to realize the effective dissipation of intermittent distributed power based on the integrated energy system, according to the characteristic that the prediction error of distributed renewable energy power decreases with the shortening of prediction time scale, the optimization dispatch is divided into two stages in this paper, namely, day-ahead dispatch and intraday rolling correction. The framework of multi-time scale coordinated and optimized dispatch of integrated energy system is shown in Figure 2.

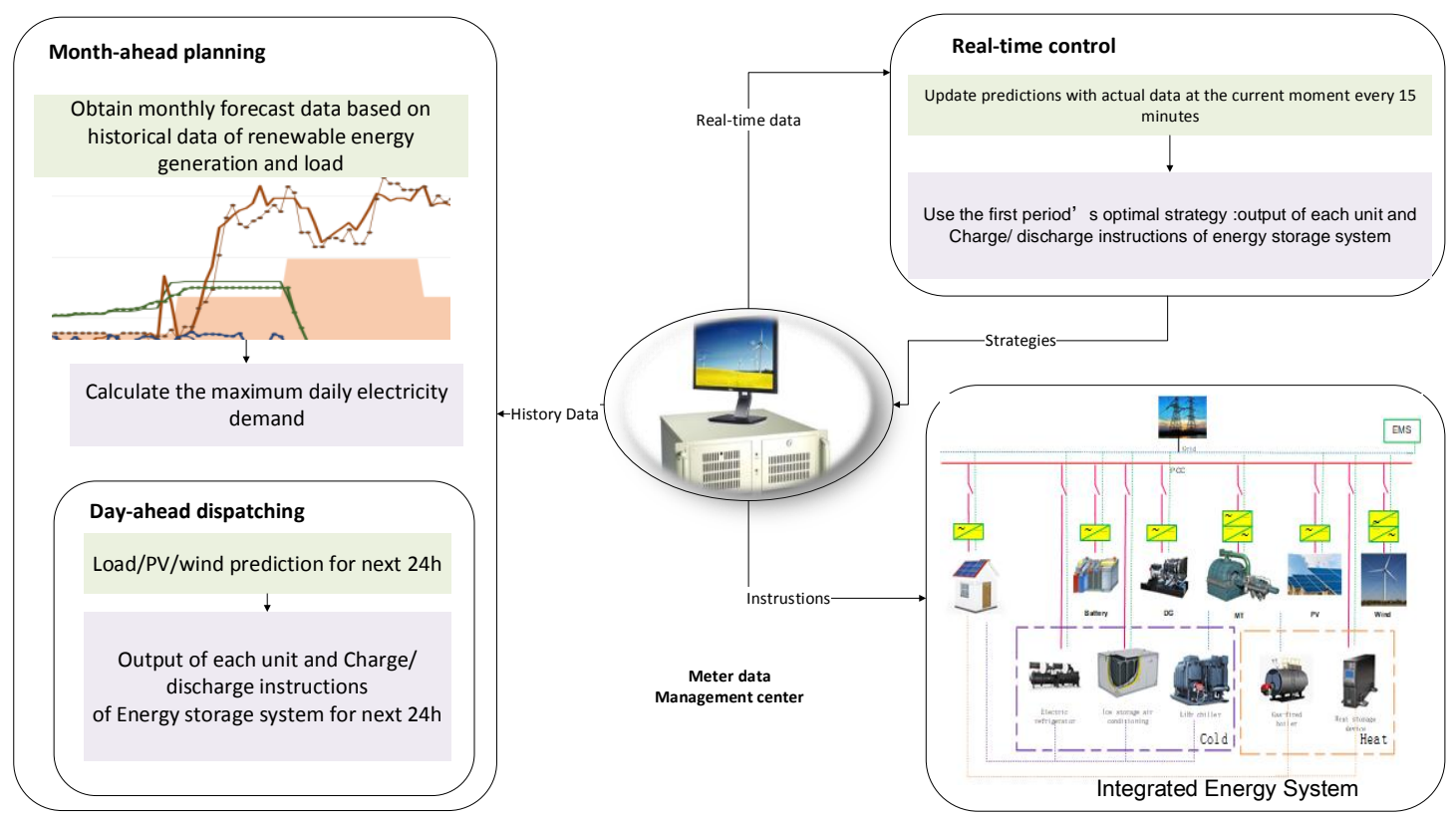

Fig. 2. The Framework of Multi-time Scale Dynamic Optimal Dispatch in Integrated Energy Systems

\subsubsection{Month-in-advance planning}

As the goal of economical optimization, the historical data of generation load, cooling load, heating load and power load of renewable energy and output trend of each component are utilized, which predicts the next month output and load demand of renewable energy to optimize the monthly operation cost of integrated energy and calculate the predicted next month maximum grid allowed capacity $\mathrm{D}$ and grid allowed buying capacity for punishment $D_{p e n}$ of integrated energy system.

\subsubsection{Day-ahead dispatch model}

Based on predictions of electrical load, cooling load and heat load in next $24 \mathrm{~h}$, aiming at reducing the operating costs to optimize, day- ahead planning generates the optimal $24 \mathrm{~h}$ (96 time segments) control strategy which fulfills the minimum daily operation cost of integrated energy system. Objective functions are as below:

$$
\begin{aligned}
& \operatorname{Min}(\cos t)=P_{E}+P_{G}+P_{C} \\
& P_{E}=\sum_{d=1}^{N_{d}} \sum_{k=1}^{N_{k}}\left(P_{\text {Grid }}(k) * P_{e}+P_{e n}(k) * P_{e} * \text { rate }-S_{\text {wind }} * P_{\text {wind }}(k)-S_{p V} * P_{p V}(k)\right) \\
& P_{G}=P_{g a s} * \sum_{d=1}^{N_{d}} \sum_{k=1}^{N_{k}}\left(\frac{P_{M T}(k)}{\eta_{M T}}+\frac{P_{G B}(k)}{\eta_{G B}}\right)
\end{aligned}
$$


$P_{C}=\sum_{d=1}^{N_{d}} \sum_{k=1}^{N_{k}}\left[\beta_{e} *\left(P_{G r i d}(k)+P_{e n}(k)\right)+\beta_{g} *\left(\frac{P_{M T}(k)}{\eta_{M T}}+\frac{P_{G B}(k)}{\eta_{G B}}\right)\right]$

Three costs are electricity purchasing cost (capacity charge, over-capacity charge and power grid operation charge), gas purchasing cost and carbon emission cost. Where $P_{e}$ is the electricity price and $P_{\text {gas }}$ is the gas price, $S_{w i n d}, S_{p V}$ are the financial subsidies of wind generation and photovoltaic generation, $P_{\text {Grid }}(k)$ is the exchanging electricity with power grid and $P_{e n}(k)$ is punished energy bought from the grid which exceed the grid allowed capacity, rate is the ratio of electric capacity penalize price, $P_{\text {wind }}(k)$, $P_{p V}(k), P_{M T}(k), P_{G B}(k)$ are the output of wind power generation, photovoltaic power generation, micro gas turbine and gas boiler at $\mathrm{k}, \eta_{M T}$ and $\eta_{G B}$ are the efficiency of micro gas turbine and gas boiler, $N_{\mathrm{d}}, N_{k}$ are the Days and periods of operation.

Day-ahead dispatch shall meet below constraints.

1) Electric power balance

$$
L O A D(k)+P_{e c}(k)+P_{c s, c}(k)=P_{\text {wind }}(k)+P_{p V}(k)+P_{M T}(k)+P_{\text {Battery }}(k)+P_{\text {Grid }}(k)
$$

Where $L O A D(k)$ is the consumed power of electrical load, $P_{c s, c}(k)$ is the electric consumption of electric refrigerator, $P_{e c}(k)$ power of electric cooling, and $P_{\text {Battery }}(k)$ is the discharge/ charge quantity of energy storage battery at $\mathrm{k}, P_{\text {Battery }}(k) \succ 0$ means energy storage system discharges, whereas energy storage system charges.

2) Thermal power balance

$$
H L O A D(k)+P_{A R}(k)+P_{h s, c}(k)=P_{H R S G}(k) * \eta_{\text {heat }}+P_{G B}(k)+P_{h s, d}(k)
$$

Where $\operatorname{HLOAD}(k)$ is the actual power of heating load, $P_{h s, c}(k), P_{h s, d}(k)$ is the charged or discharged heat of heat storage device at $\mathrm{k}, P_{A R}(k)$ is the consumed heat of lithium bromide compressor, $P_{H R S G}(k)$ is the consumed heat of heat recovery steam generator and $\eta_{\text {heat }}$ is the conversion efficiency of waste heat of micro gas turbine.

3) Cooling power balance

$$
C L O A D(k)=P_{A R}(k) * \eta_{c o l d}+P_{e c}(k)+P_{c s, d}(k)
$$

Where $C L O A D(k)$ is real power of cooling load, $P_{c s, d}(k)$ is the cooling power of ice storage air conditioning at $\mathrm{k}$, and $\eta_{\text {cold }}$ is cooling efficiency of lithium bromide compressor.

4) Output unit power constraints

$$
\begin{aligned}
& P_{n \text { min }}^{k} \leq P_{n}^{k} \leq P_{n \text { max }}^{k} \\
& \left|P_{n}^{k}-P_{n}^{k-1}\right| \leq \text { rate }_{n}
\end{aligned}
$$

Where $P_{n \text { min }}^{k}, P_{n \text { max }}^{k}$, rate $_{n}$ are respectively upper limit, lower limit and ramp speed of power of controllable components, such as gas turbine, gas boiler, electric chiller, absorption chillers, energy 
storage device and etc.

5) Energy storage equipment constraint

$$
\begin{aligned}
& E_{x}^{0}=E_{x}^{e n d} \\
& E_{x}^{k+1}-E_{x}^{k}=\left(E_{x, c}^{k} * \eta_{x, c}-\frac{E_{x, d}^{k}}{\eta_{x, d}}\right) * \Delta t \\
& 0 \leq E_{x, c}^{k}+E_{x, d}^{k} \leq E_{x, d}^{\max } \\
& \operatorname{Soc}_{n \min }^{k} \leq \operatorname{Soc}_{n}^{k} \leq \operatorname{Soc}_{n \max }^{k}
\end{aligned}
$$

Where $\mathrm{x}$ is the type of energy, which can be power, heat and cold energy. $E_{x}^{0}$ is the energy storage quantity of energy storage equipment at initial time, $E_{x}^{e n d}$ is the energy storage quantity at end of dispatch. $E_{x}^{k+1}$ is the energy storage quantity after energy charge/ discharge, $E_{x}^{k}$ is the energy storage quantity before energy charge/ discharge, $E_{x, c}^{k}, E_{x, d}^{k}$ is the power of energy charge/ discharge at $\mathrm{k}, \eta_{x, c}$ and $\eta_{x, d}$ is efficiency of energy charge and energy discharge respectively. Equation13 means equipments' state of charge at k should meet the requirements of minimum $S_{n \text { min }}^{k}$ and maximum $\operatorname{Soc}_{n \text { max }}^{k}$.

Here, $S o c_{\min }=0.2, S o c_{\max }=0.8, S o c_{0}=0.2$ are taken generally for battery energy storage system. And $S o c_{\min }=0.2, S o c_{\max }=0.9, S o c_{0}=0.3$ are taken generally for heat or cold storage device.

6) Electricity purchasing constraints

$$
\begin{aligned}
& 0 \leq P_{\text {Grid }}(k) \leq D * \Delta t \\
& 0 \leq P_{e n}(k) \leq D_{\text {pen }} * \Delta t
\end{aligned}
$$

Where $\mathrm{D}$ is the maximum grid allowed capacity and $D_{p e n}$ is grid allowed buying capacity for punishment.

\subsubsection{Short-time online optimization}

Horizon of operation window is 96, and optimization step is $15 \mathrm{~min}$ for MPC algorithm. Based on the day-ahead planning, according to the current data of power load, heat load, cooling load, photovoltaic power generation and wind power generation of buildings collected by monitoring system, MPC algorithm replaces predicted data by the real-time value, and optimizes to generate a new optimal control strategy for minimization of $24 \mathrm{~h}$ (96 time segments) daily operation cost. The control strategy of first time segments is utilized into practical operation of system to correct day-ahead planning.

\subsubsection{Solution}

Objective functions and constraints of optimization strategy are linear, which the variables of optimization are real number or integer variables. Therefore, optimization algorithm can apply mixedinteger linear programming model and solve this kind of problem with MATLAB intlinprog.m.

\section{Case Study}

A small integrated energy system of a park in Beijing is taken as an example to analyze. In this system, the installed capacity of photovoltaic power generation is $58.25 \mathrm{kWp}$, which is composed by 6 
photovoltaic arrays. The installed capacity of main transformer of electric building is $1 \mathrm{MW}$, the actual peak of load power is about $300 \mathrm{MW}$, the average of load power is about $200 \mathrm{MW}$. The rated capacity of virtual energy storage system is $100 \mathrm{kWh}$, and DC voltage is $500 \mathrm{~V}$, which is composed by $3.2 \mathrm{~V}-1.1 \mathrm{AH}$ standard lithium iron phosphate battery and experiential model of $2 \mathrm{~V}-500 \mathrm{AH}$ lead-acid battery with series and parallel connection. The parameters of other components in this system are as following.

Table 1. Parameters of key components

\begin{tabular}{llll}
\hline Distributed energy source & $\begin{array}{l}\text { Lower limit of output } \\
(\mathrm{kW})\end{array}$ & $\begin{array}{c}\text { Upper limit of output } \\
(\mathrm{kW})\end{array}$ & $\begin{array}{l}\text { Ramp speed } \\
(\mathrm{kW} / \mathrm{min})\end{array}$ \\
\hline Photovoltaic energy source & 0 & 58.25 & 50 \\
Energy storage battery & 0 & 100 & 25 \\
Micro gas turbine & 0 & 75 & 20 \\
Gas boiler & 0 & 100 & 20 \\
Heat recovery steam generator & 0 & 60 & 18 \\
Lithium bromide compressor & 0 & 30 & 20 \\
Ice storage air conditioning & 0 & 50 & 20 \\
Heat storage device & 0 & 50 & 25 \\
Electric refrigerator & 0 & 50 & 25 \\
\hline
\end{tabular}

The financial subsidy of photovoltaic generation is taken $0.42 \mathrm{CNY} / \mathrm{kWh}$, the financial subsidy of wind generation is taken $0.5 \mathrm{CNY} / \mathrm{kWh}$, and the output of wind generation and photovoltaic generation are not over $40 \%$ load demand, therefore, the generated power is not sold to power grid, which is supplied to domestic load completely. Electricity price in Beijing is showed in table 2.

Table 2. Electricity price in Beijing

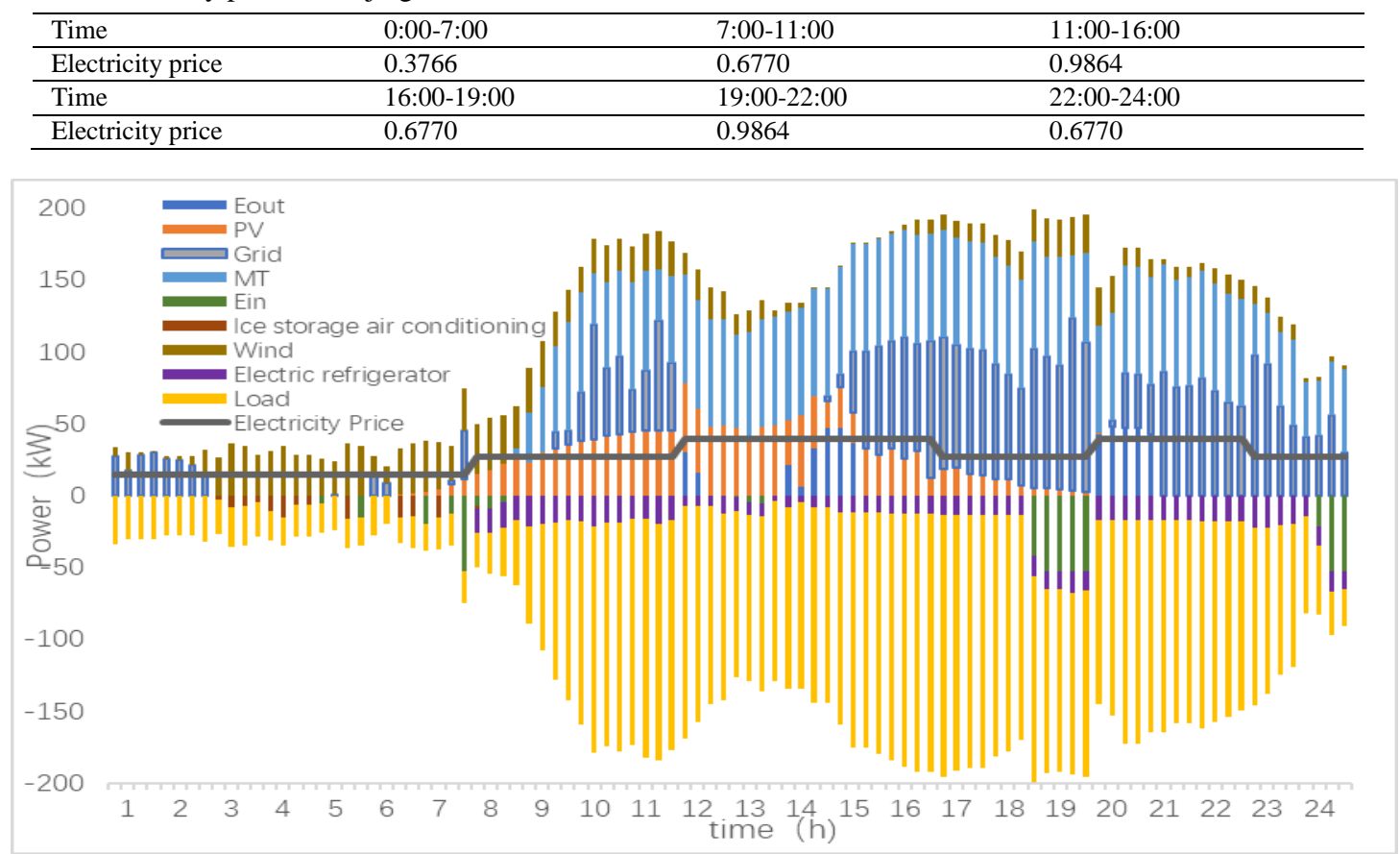

Fig. 3. Typical day-ahead unit output plan for electricity load in summer

The buildings in the park are opened from 7:00 to 24:00. As shown in Figure 3, during the period of low electricity price, the electric load is mainly satisfied by purchasing power from the grid, and the energy storage devices are charged. In the period of peak price, to reduce operating costs, electricity is mainly supplied by gas turbines, and wind power and photovoltaic power are completely consumed. If it is still insufficient, electricity will be purchased from the grid. Besides, the electricity storage devices 
discharge at the electricity price peak to reduce operating costs and relieve power supply pressure.

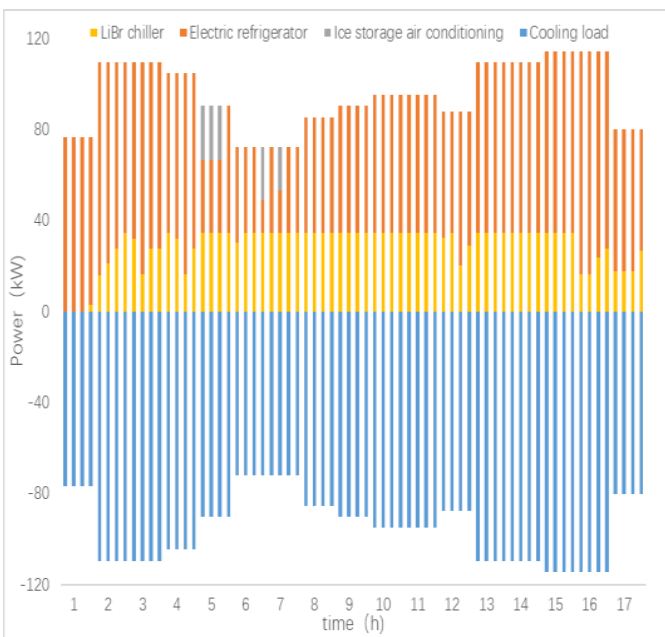

(a)

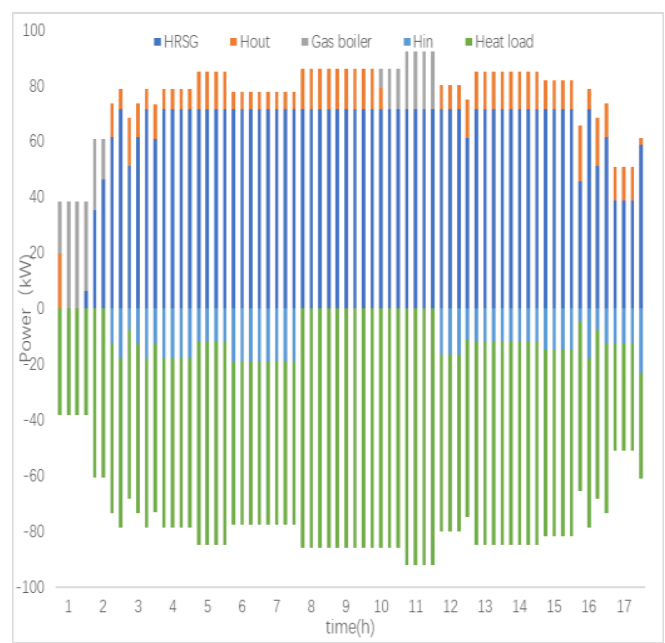

(b)

Fig. 4. Typical day-ahead unit output plan in summer: (a) cooling load (b) heat load.

As can be seen in Figure 4, in the period of low electricity price, the heat load is mainly satisfied by boiler, and the cooling load by electric refrigerator. During the period of high electricity price, heat storage devices and ice storage air conditioners release energy, and the heat load is mainly met by the gas turbine, since in this period the gas turbine generates a large amount of electricity and heat; due to the restriction of the maximum power of absorption chiller, the cooling load is also satisfied by electric refrigerator.

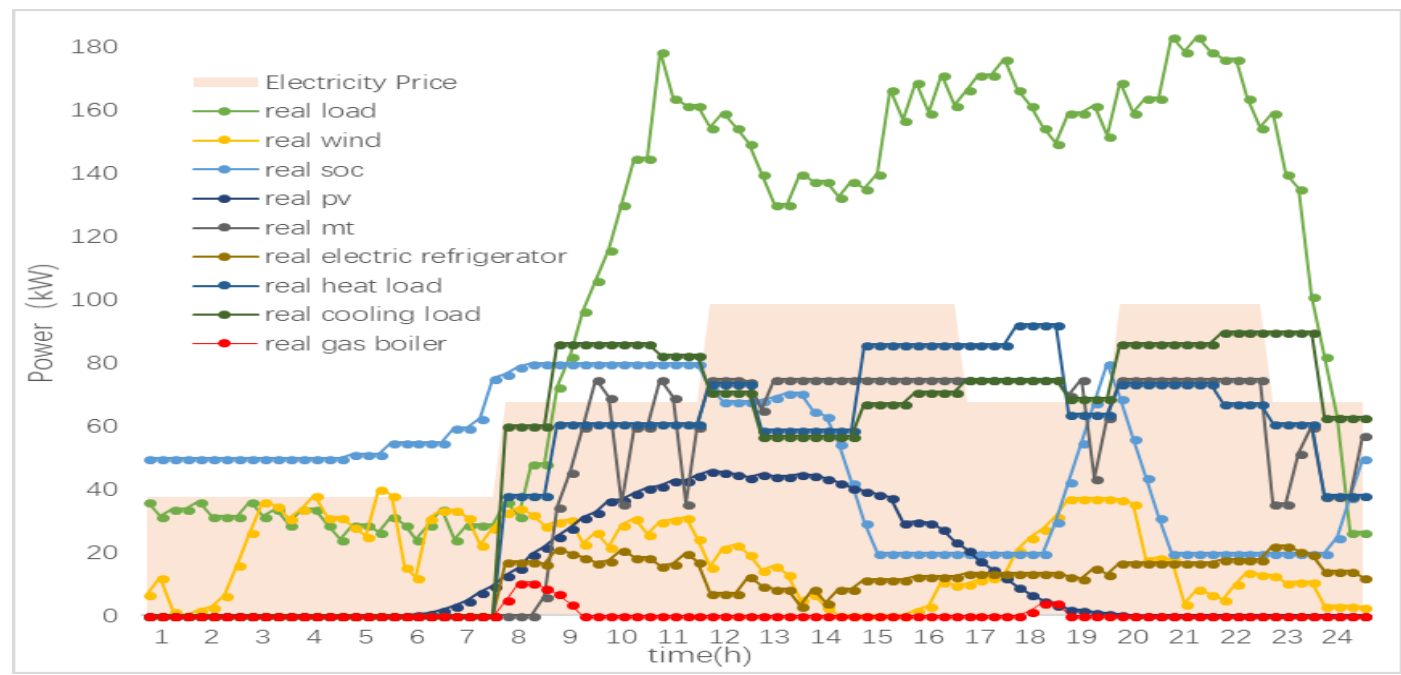

Fig. 5. Real-time load demand and actual contribution of each unit

In the optimization of short-term MPC, feedback correction fulfills the optimization based on the practical operation of system, which is to make a relatively accurate prediction for future dynamic behavior of system. Therefore, the output planning of each component is corrected to meet each requirement of current loads and reduce the residual output according to the short-term optimization. Real-time load demand and actual contribution of each unit are showed in Fig. 5.

After one month operation in the park, comparing with the operation cost which carries out the dayahead operation planning and short-term MPC planning, it proves that the real-time prediction, rolling 
horizontal optimization and feedback correction of MPC algorithm correct the error of prediction timely, which can improve the economy of system operation. Monthly operation cost of integrated energy system without energy storage system cost is showed in Table 3.

Table 3. Monthly operation cost of integrated energy system without ESS cost

\begin{tabular}{lcl}
\hline Optimization mode & day-ahead dispatch & short-term MPC control \\
\hline Electricity purchasing cost & 15006.55 & 14655.30 \\
Gas purchasing cost & 26037.45 & 25302.15 \\
Carbon emission cost & 7729.05 & 7301.20 \\
Total cost & 48773.05 & 47258.65 \\
\hline
\end{tabular}

\section{Conclusion}

In this paper, the optimized operation model of the integrated energy system is established with overall consideration of three aspects, namely, electricity purchasing cost, gas purchasing cost and carbon emission cost: 1) Mutual replacement of electricity and gas energy, and coordinated \& optimized operation of various energy conversion equipment, can achieve energy cascade utilization, promote multienergy complementarity, reduce operating costs and carbon emissions, and also promote the local consumption of new energy; 2) The use of energy storage devices achieves energy time-sequence transfer, eases the energy supply pressure and reduce operating costs.

Coordinated dispatch of multiple time-scale optimization is applied, which has characteristics as following: 1) month-in-advance plan obtains the maximum electricity demand to plan in advance, which not only ensures the uninterrupted power for important load, but also reduces the operation cost. 2) Startup \& shutdown plan of each unit and basic output are obtained by day-ahead optimization. 3). Shortterm MPC optimization fine regulates the output of unit with feedback correction to satisfy the real-time operation and improve the economy of system operation.

\section{References}

[1] Afram A, Janabi-Sharifi F. Theory and applications of HVAC control systems - A review of model predictive control (MPC). Building and Environment. 2014, 72.

[2] Xu X, Jin X, Jia H, et al. Hierarchical management for integrated community energy systems. Applied Energy. 2015; 160: 231-243.

[3] Mayhorn ET, Kalsi K, Elizondo MA, et al. Optimal Control of Distributed Energy Resources using Model Predictive Control[C]. United States: IEEE, Piscataway, NJ, United States(US)., 2012.

[4] Z. C, Y. Z, T. Z. An intelligent control approach to home energy management under forecast uncertainties. 2015.

[5] Vu T, Paran S, El-Mezyani T, et al. Model Predictive Control for Power Control in Islanded DC Microgrids. 2015.

[6] K. K, P. H, W. H, et al. Comparative study of integrated energy system modelling. 2017.

[7] Ma J, Qin J, Salsbury T, et al. Demand reduction in building energy systems based on economic model predictive control. Chemical Engineering Science. 2011, 67(1).

[8] A Model Predictive Control Based Distributed Co ordination of Multi-microgrids in Energy Internet[J]. Journal of Automation. 2017; (8): 1443-1456.

[9] Liao MY. Economic Analysis of CCHP System Based Microgrid [D]. South China University of Technology, 2014.

[10] Guo LY, Zong Y, Jiang YW, et al. Optimal operation of multi-source micro-grid considering demand response. Distribution \& Utilization. 2017; 34(12): 8-14.

[11] Ma TF, Wu JY, Hao LL, et al. The energy flow modeling and optimal operation analysis of micro energy grid based on energy hub. Power System Technology. 2018; (01): 179-186.

[12] Zeng M, Peng LL, et al. Economic Optimization and Corresponding Algorithm for Distributed Energy System CompatibleWith Demand-Side Resources. Power System Technology. 2016; (06): 1650-1656.

[13] P. A J, W. Z, X. N, et al. Real-Time Energy Management Optimization Using Model Predictive Control on a Microgrid Demonstrator. 2017. 